\title{
Material Properties of Laser-Welded Thin Silicon Foils
}

\author{
M. T. Hessmann, ${ }^{1}$ T. Kunz, ${ }^{1}$ M. Voigt, ${ }^{1,2}$ K. Cvecek, ${ }^{3}$ M. Schmidt, ${ }^{3}$ A. Bochmann, ${ }^{4}$ \\ S. Christiansen, ${ }^{5}$ R. Auer, ${ }^{1}$ and C. J. Brabec ${ }^{1,2}$ \\ ${ }^{1}$ Bavarian Center for Applied Energy Research (ZAE Bayern), Haberstraße 2a, 91058 Erlangen, Germany \\ ${ }^{2}$ Institute Materials for Electronics and Energy Technology (i-MEET), University of Erlangen-Nuremberg, Martensstrße 7, \\ 91058 Erlangen, Germany \\ ${ }^{3}$ BLZ-Bavarian Laser Center, Konrad-Zuse-Straße 2-6, 91052 Erlangen, Germany \\ ${ }^{4}$ University of Applied Sciences Jena, Carl-Zeiss-Promenade 2, 07745 Jena, Germany \\ ${ }^{5}$ Max-Planck-Institute for the Science of Light, Günther-Scharowsky-Straße 1, 91058 Erlangen, Germany
}

Correspondence should be addressed to M. T. Hessmann; hessmann@zae.uni-erlangen.de

Received 22 May 2013; Accepted 30 June 2013

Academic Editor: Leonardo Palmisano

Copyright (c) 2013 M. T. Hessmann et al. This is an open access article distributed under the Creative Commons Attribution License, which permits unrestricted use, distribution, and reproduction in any medium, provided the original work is properly cited.

\begin{abstract}
An extended monocrystalline silicon base foil offers a great opportunity to combine low-cost production with high efficiency silicon solar cells on a large scale. By overcoming the area restriction of ingot-based monocrystalline silicon wafer production, costs could be decreased to thin film solar cell range. The extended monocrystalline silicon base foil consists of several individual thin silicon wafers which are welded together. A comparison of three different approaches to weld $50 \mu \mathrm{m}$ thin silicon foils is investigated here: (1) laser spot welding with low constant feed speed, (2) laser line welding, and (3) keyhole welding. Cross-sections are prepared and analyzed by electron backscatter diffraction (EBSD) to reveal changes in the crystal structure at the welding side after laser irradiation. The treatment leads to the appearance of new grains and boundaries. The induced internal stress, using the three different laser welding processes, was investigated by micro-Raman analysis. We conclude that the keyhole welding process is the most favorable to produce thin silicon foils.
\end{abstract}

\section{Introduction}

Cost reduction is a major topic in the photovoltaic research and industry. One appropriate way to reduce costs within the production chain of silicon solar cells is to reduce kerf losses. The ZAE Bayern developed a method of producing an extended monocrystalline silicon base foil with a thickness of ca. $50 \mu \mathrm{m}$ as depicted in Figure $1[1,2]$. This base foil is manufactured by laser welding of several individual thin wafers. This will make it possible to produce an endless substrate which is feasible for a roll to roll process. By applying a layer transfer process as porous silicon (PSI) $[3,4]$, an appropriate layer can be detached from the base foil without sawing. In detail, on the surface of silicon two porous layers will be established; one layer will serve as a predetermined breaking layer, and the other as a seed layer for a large area epitaxial process which will be applied after an annealing step [5]. Following these steps, a solar cell layer can be detached from the extended monocrystalline silicon base foil. It is only necessary to use silicon wafer-based substrates once to assemble the extended monocrystalline silicon base foil. Furthermore, layers for solar cell devices will be produced by a layer transfer technique and a large area epitaxy from the extended monocrystalline silicon base foil. Further information about the solar cell manufacturing process is published elsewhere [1].

In addition, the threshold of float-zone (FZ)-grown silicon crystals is not valid anymore for this kind of process. The size restrictions of ingot fabrication of FZ silicon lies at the moment by 8 inchs in diameter and could be overcome by producing an extended monocrystalline silicon base foil. This would open a new field of large area substrates and processing. Moreover, a further reduction of material losses during the processing could be achieved.

The concept combines the low production costs of thin film solar cells with the high efficiencies of FZ-grown silicon 


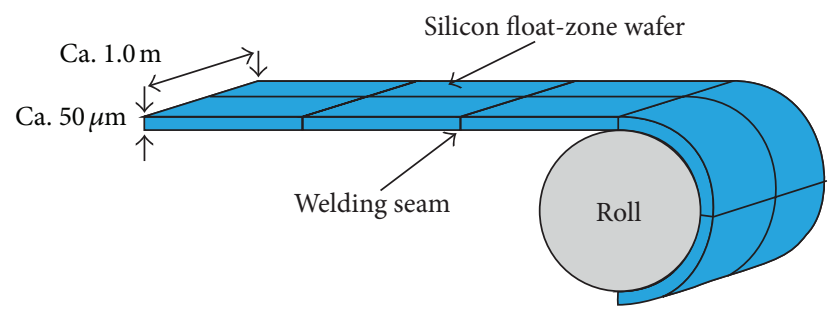

FIGURE 1: Illustration of the extended monocrystalline silicon base foil, which is welded together by individual silicon float-zone wafers, for further information for the solar cell manufacturing process please see [1].

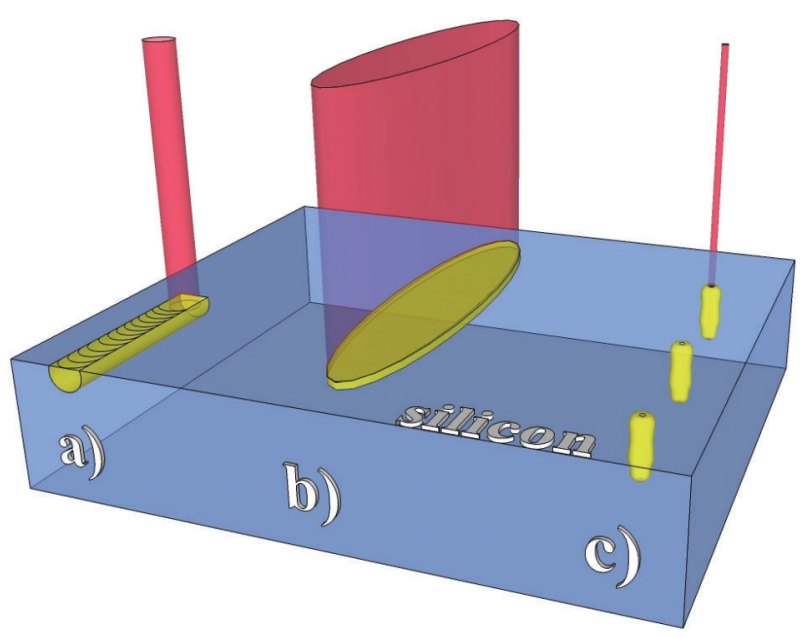

FIGURE 2: Application principle for laser welding: (a) Laser spot welding with low constant feed speed (b) Laser line welding (c) Keyhole welding. Laser beams are illustrated in red and areas which are influenced by the laser beam are colored in yellow.

solar cells. Recently, high cell efficiencies of $19.1 \%$ have been demonstrated by Petermann et al. [6] for the PSI approach on a Czochralski-grown substrate.

It is essential for the extended monocrystalline silicon base foil to create a lateral bonding of silicon wafers to achieve an endless belt-like substrate. In general, the study of lateral joining of silicon is still in the early stages. Concepts as the lateral epitaxy were introduced in the past, but no experimental data had been published as far as we know [7]. Preliminary laser spot welding tests of silicon were done by Kaufmann [8]. For a good quality of bonding, it is essential to have a well-defined surface structure, an absence of particles, and a very low surface roughness [9].

In our current work we show the recent progress of laser welding of thin silicon foils on a laboratory scale. The size of welded silicon will be scaled up in order to make a roll to roll process feasible [1]. We compared spot welding with a low constant feed speed, line welding (both at room temperature), and keyhole welding at preheated samples of $1000^{\circ} \mathrm{C}$ (see Figure 2). After the welding process the area which was irradiated by the laser was characterized by electron backscatter diffraction (EBSD) for revealing changes in the grain structure and micro-Raman analysis for visualizing induced internal stress by the laser welding process.

\section{Material and Methods}

2.1. Sample Preparation. Samples of 5-inch-FZ silicon wafers had been prepared, with (100)-orientation, one side polished, p-type, with a thickness of $280 \pm 15 \mu \mathrm{m}$ and a resistivity of $0.50 \pm 0.06 \Omega \mathrm{cm}$. All wafers were cut by laser into square pieces. To receive a thin and flexible base foil substrate, the sample thickness was decreased to ca. $50 \mu \mathrm{m}$ by etching with potassium hydroxide $(\mathrm{KOH})$. Additionally, this step removes laser damage from the edges which is very important to strengthen the mechanical stability. After the $\mathrm{KOH}$ etching, all samples were cleaned by an RCA process.

2.1.1. Laser Spot Welding with Low Constant Feed Speed. For each welding process, two $19 \times 17 \mathrm{~mm}^{2}$ samples were mounted in lap joint configuration onto a motorized 4axis system, which consists of one rotary and three linear stages. The laser source was a single mode fiber laser model YLR-200-SM built by the company IPG Photonics with a wavelength of $1070 \mathrm{~nm}$, operating at a power of $30 \mathrm{~W}$, a duty cycle of $50 \%$ with a frequency of $2.5 \mathrm{kHz}$, and a laser spot diameter on the silicon surface of $300 \mu \mathrm{m}[10,11]$. During the welding process the aligned samples on the sample holder were moved relative to the stationary laser beam with a feed speed of $1 \mathrm{~mm} / \mathrm{s}$ (at room temperature).

2.1.2. Laser Line Welding. Two $19 \times 17 \mathrm{~mm}^{2}$ samples were placed in lap joint configuration within the focal area of the laser line at room temperature. The laser source for this welding process was the same as used for laser spot welding. By using a cylindrical lens and a microlens array in a homogenizer-like setup, the nearly Gaussian intensity distribution generated by the used laser was transformed into the laser line (for further details see [12]). The resulting laser line had a dimension of ca. $25 \mathrm{~mm}$ in length and ca. $700 \mu \mathrm{m}$ in width at the focus level. Therefore, no movements of samples or laser beam were necessary. For the laser line welding process the power of the laser was increased linearly from $0 \mathrm{~W}$ to $141 \mathrm{~W}$ within $5 \mathrm{~s}$. After reaching $141 \mathrm{~W}$, the value was kept for $1 \mathrm{~s}$ and afterwards decreased linearly to $0 \mathrm{~W}$ within $1 \mathrm{~s}$.

2.1.3. Keyhole Welding. Two samples (each $25 \times 25 \mathrm{~mm}^{2}$ ) were aligned in butt joint configuration, and a third one $(25 \times$ $25 \mathrm{~mm}^{2}$ ) was placed centering on the back of the other two samples. This geometry was chosen because a normal butt joint configuration with two samples was not satisfactory. They were mounted on a sample holder consisting of quartz glass and then heated to $1015^{\circ} \mathrm{C}$ under nitrogen atmosphere. A laser beam irradiated the samples in the oven through a quartz glass window. The laser source was a single mode, continuous wave $1075 \mathrm{~nm}$ Yb-fiber laser, model YLR-1000SM made by company IPG Photonics and operated at a power of $260 \mathrm{~W}$ (maximum power $1000 \mathrm{~W}$ ). A galvanometer scanner system was used to focus and deflect the laser 
beam onto the sample. The focal length of the objective was $370 \mathrm{~mm}$, which resulted in an $80 \mu \mathrm{m}$ spot diameter of the laser beam on the surface of the sample. The feed speed using the galvanometer scanner was $550 \mathrm{~mm} / \mathrm{s}$. Further details are described elsewhere [13].

2.2. Setup for Micro-Raman Measurements. An Alpha500 AR microscope from WITec GmbH, Ulm (Germany), was used for micro-Raman characterization. The microscope has a motorized sample stage of $150 \mathrm{~mm} \times 100 \mathrm{~mm}$ and a piezo-driven stage of $100 \mu \mathrm{m} \times 100 \mu \mathrm{m} \times 20 \mu \mathrm{m}$ for fine measurements. The laser source is a Nd:YAG laser with an excitation wavelength of $532 \mathrm{~nm}$. The measurements were carried out at an output power of $10 \mathrm{~mW}$. The spectrometer is equipped with a Peltier-cooled CCD detector and an 1800 lines $/ \mathrm{mm}$ grating. A magnification of 50 with a numerical aperture of 0.75 was used for the measurements. With this, we receive a spot size of less than $1 \mu \mathrm{m}$ and a penetration depth in silicon of ca. $0.5 \mu \mathrm{m}$. All measurements of the cross-section of welded samples were carried out by using backscattering geometry at room temperature.

The software WITec Project was used for the evaluation of the recorded data. Peak parameters were determined by fitting Lorentz curves.

2.3. Setup for Electron Backscatter Diffraction (EBSD). A FIB-SEM LYRA ${ }_{X M U}$ system manufactured by the company TESCAN (Brno, Czech Republic) was used for EBSD analysis. The system is equipped with an EDAX/TSL "OIM XM4". For a good electrical contact between the measurement setup and the samples, all cross-sections were coated with a $10-20 \mathrm{~nm}$ carbon layer by sputtering. During the measurements, the samples were tilted by $70^{\circ}$. Properties of the electron beam were set to $30 \mathrm{keV}$ electron beam energy and 5-12 nA beam currents, which results in a spot size of ca. 500-700 nm. The EBSD measurement was performed by an integration time of $25-80 \mathrm{~ms}, 4 \times 4$ pixel binning, and $3 \mu \mathrm{m}$ step size. Scanned areas are in the range of ca. $300 \mu \mathrm{m} \times 500-1000 \mu \mathrm{m}$. As a software, EDAX/TSL Data Analysis 5.31 was used.

\section{Results}

For the purpose of revealing material changes within the silicon after laser beam irradiation, we analyzed cross-sections of welded samples by micro-Raman as well as EBSD. Plotting the micro-Raman data as a Lorentz peak area mapping reveals changes in the crystal structure of the irradiated silicon; the peak area is sensitive to the crystal orientation [14]. Furthermore, we applied an EBSD scan to determine the value of the crystal orientation of each grain in detail. To evaluate the stress caused by the laser processing, we derived the internal stress from mappings of the Raman frequency shift. For this purpose the following approximation is used, which is derived from silicon (100) under biaxial stress [15, 16]:

$$
\sigma(\mathrm{MPa})=-250\left(\omega_{s}-\omega_{r}\right) \quad[1 / \mathrm{cm}],
$$

where $\omega_{s}$ is the peak position with stress, respectively $\omega_{r}$ without stress. The depicted maximum values are with respect to the $5 \%$ and $95 \%$ thresholds of $\omega_{s}$ for tensile stress and compressive stress.

3.1. Laser Spot Welding with Low Constant Feed Speed. After applying laser spot welding to $50 \mu \mathrm{m}$ thin silicon foils, structural changes within the silicon can be observed as shown in Figure 3. A crack can be seen in the left part of Figure 3(a). The welding region is mapped on the right side of the figure. The depicted shaded areas within the image next to the welding region are newly formed grains. Areas of silicon foil 1 which were underneath the silicon foil 2 during the laser irradiation and were not irradiated directly show no structural changes. For the same position of the sample, an EBSD scan was applied which is shown in Figure 3(b).

The EBSD mapping reveals a shift in crystal orientation and the presence of new grains in the material at the welding seam. An area of about $300 \mu \mathrm{m}$ shows this appearance with different crystal orientations, which is correlated to the diameter of the irradiated laser beam. The whole affected area is not shown because of the high magnification of Figure 3 . Newly formed grain boundaries are mostly $\Sigma 3$ and $\Sigma 9$ twin boundaries.

As can be seen previously, the laser beam impact into the silicon material causes material changes. The internal stress mapping shows a stress distribution within the welding region for laser spot welding as depicted in Figure 3(c). The inserted stress by laser irradiation appears only at locations where newly formed grains along the junction of the welding partners can be found in the EBSD mapping. The maximum tensile stress was 19.2 MPa and -90.5 MPa compressive stress, respectively.

Within this approach the welding partners undergo major structural changes around the welding seam. It is very likely that the laser-irradiated area was completely molten during the welding process and recrystallized afterwards during the cooling procedure. Only monocrystalline areas could be found in regions which were not laser irradiated directly and where the heat transition had to overcome the gap between the stacked silicon wafers.

3.2. Laser Line Welding. The result of lap joint welding using a laser line focus is depicted in Figure 4. No newly formed grains are observed in the EBSD mapping (Figure 4(a)) around the welding region so that the sample remains monocrystalline. However, the two welding partners don't have exactly the same crystal orientation. Although the laser irradiated area is bigger in width (ca. $700 \mu \mathrm{m}$ ) than by laser spot welding (ca. $300 \mu \mathrm{m}$ ), no evidence of crystal structural changes has been found. The correlation between the laser beam diameter and material changes is not as strong as for laser spot welding. Remarkable for the laser line welding is the growth in thickness of the welding partners around the welding seam.

Raman stress analysis in Figure 4(b) shows a very homogenous mapping. Within the laser-irradiated area, maximum values of tensile stress of $13.0 \mathrm{MPa}$ and compressive 


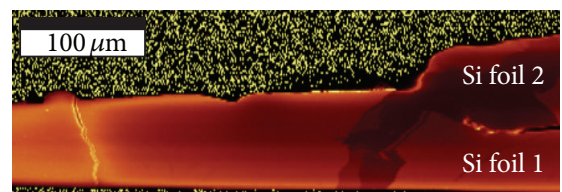

(a)
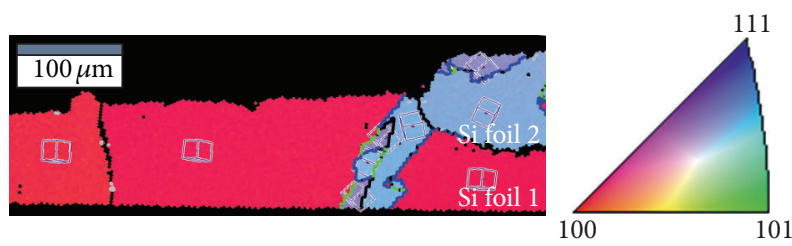

(b)

$125 \mathrm{MPa}$

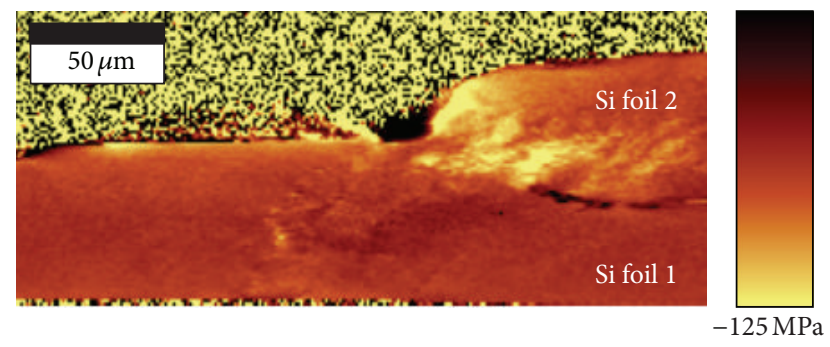

(c)

FIgURE 3: Cross-sections mappings of a spot welded sample, the laser beam was introduced from the top side. (a) Plot of the microRaman Lorentz peak area in arbitrary units. (b) EBSD mapping, color with respect to the wafer surface, grain boundaries are colored as followed: $\Sigma 3$ in blue, $\Sigma 9$ in green and angles between $15.0^{\circ}$ to $62.8^{\circ}$ in black. Definitions for the crystal orientation are plotted in the color coded map on the right side and as cubes within the mapping. (c) Micro-Raman internal stress mapping, maximum compressive stress of $-90.5 \mathrm{MPa}$ and tensile stress of 19.2 $\mathrm{MPa}$ are determined.

stress of $-21.5 \mathrm{MPa}$ are determined. Compared to the laser spot welding, the stress is lower.

We assume that the thickening of the welding partners at the welding region appears due to wetting and surface tension issues. It seems like the molten silicon flows towards the solid silicon, so that the thickening develops. The difference in crystal orientation is probably due to an unavoidable misalignment of the samples to each other by mounting the samples on a motorized sample holder system before welding. The absence of structural changes within the silicon material after the laser beam irradiation could be addressed to the broad irradiation and the reduced penetration depth by the laser line welding technique.

3.3. Keyhole Welding. Two samples are aligned on a quartz glass sample holder in a butt joint configuration, and a third one was placed centered on the back side of the other two. The sample holder was placed in an oven and heated up to $1015^{\circ} \mathrm{C}$ under nitrogen atmosphere. The laser beam for welding was introduced through a quartz window in the oven from the top side. Three bonding areas had been created and are shown in Figure 5; the areas between silicon foil 1 and 2
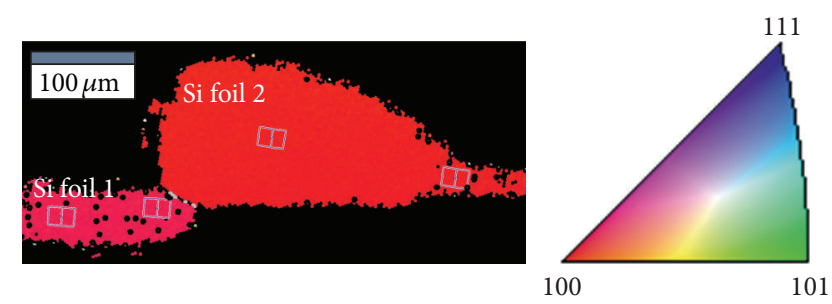

(a)

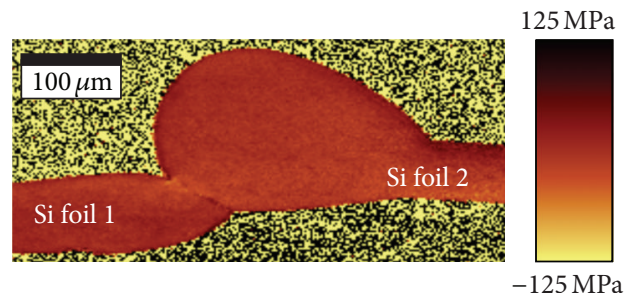

(b)

FIgURE 4: Cross-section mappings of a laser line welded sample, laser irradiation was introduced from the top side (a) EBSD mapping, color with respect to the wafer surface, crystal orientations as shown in the color map and the included cubes (b) Internal stress mapping measured by mirco-Raman, maximum compressive stress of $-21.5 \mathrm{MPa}$ and tensile stress of 13.0 MPa are observed.

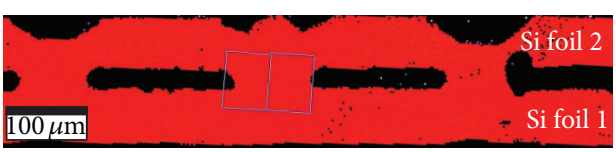

(a)

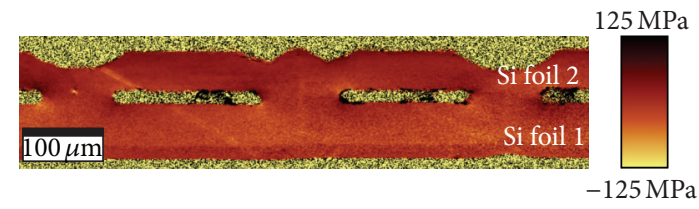

(b)

FIGURE 5: Cross-section mappings of a keyhole welded sample, three welding areas are illustrated and the laser beam was applied from the top side (a) EBSD mapping, color with respect to the wafer surface, crystal orientations as shown in the color map as well as the included cube (b) Internal stress mapping measured by micro-Raman, maximum compressive stress of $-50.0 \mathrm{MPa}$ and tensile stress of $27.5 \mathrm{MPa}$ are measured.

next to the welding areas are gaps because keyhole welding is not a continuous laser process. The EBSD mapping (see Figure 5(a)) shows a very homogenous crystal structure after the welding process. No evidence of newly formed grains and grain boundaries can be observed. The crystal orientation remains the same. On the top, the two holes and one elevation of the top sample are caused by the high laser beam intensity within an area of about $80 \mu \mathrm{m}$. Furthermore, no thickening of the silicon material is observed after welding contrary to using a laser line. 
The internal stress mapping, depicted in Figure 5(b), is very homogenous and shows only tiny areas of increased stress, and the bright angular lines are due to cross-section preparation. Maximum compressive stress of $-50.0 \mathrm{MPa}$ and tensile stress of $27.5 \mathrm{MPa}$ had been determined. Those values are higher than stress values of laser line welding, but lower than values of laser spot welding.

The recent welding approach shows no multiple grain appearance. No material thickening at the welding seam can be observed. Only locally at the back side, formations of valleys and mountains can be observed which is due to the high laser irradiation on small an area to create keyholes. These connect the stacked silicon wafers without creating structural changes within the material. During the cooling procedure after irradiation all four neighboring points next to the keyholes with silicon in the solid state serve as seed layers for the recrystallization process, so that the laser-irradiated areas recrystallize into a monocrystalline structure.

\section{Discussion}

Although welding of silicon wafer material is very challenging, we could show three different approaches. Using a spot welding process with low constant feed speed at room temperature has been successfully demonstrated, but this welding process suffers from the formation of new grains within the welding seam. Two scenarios are feasible to explain this appearance of new grains. By mounting the samples onto the sample holder, an inevitable misalignment is expected; this should lead to at least one grain boundary between the two welding partners. Additionally, the cooling procedure after the welding process plays a dominant role for developing new grains. In this case an area of ca. $300 \mu \mathrm{m}$ is completely molten during the welding process; silicon phase boundaries on the left and right sides of the molten area are very small as compared to the area which is molten. Therefore, the monocrystalline silicon material on the left and right sides of the molten area cannot be the seed layer of the whole molten area because the cooling at the top and bottom sides as well as the transition back to the solid state will happen too fast. Thus, secondary seeding occurs, and grain boundaries appear. A $300 \mu \mathrm{m}$ wide area of different grains develops during the welding procedure. However, micro-Raman measurements determine high compressive stress values, which could be a problem for the mechanical stability of the silicon foil. Breaking tests of thin silicon foils with similar geometry determine an average breaking stress of $287.5 \mathrm{MPa}$ as published elsewhere [1]. Breakage of an extended monocrystalline silicon base foil would cause major problems in a roll to roll process. Thus, this technique is not suitable for producing silicon foils.

Applying the welding process by using a laser line at room temperature is realized. Unfortunately, this way of welding suffers from thickening at the welding seam. Experiments with preheated welding samples show that the effect of thickening remains. Presumably, this is caused by wetting problems and differences in surface tension. This can be explained by the rule of Eötvös [17, 18], which states that the surface tension of a fluid decreases at increasing temperature.
Applying the laser line on the silicon causes a low heating rate due to the wide irradiated area, so that temperature gradients occur due to thermal conduction. At the outer irradiated area the surface tension is higher than that at the middle of the irradiated area. If the duration of the melting process for the silicon had been long enough, the molten silicon in the middle of the irradiated area flows towards the solid silicon and accumulates. Hence, the thickening occurs at the welding seam by welding using a laser line. However, one more effect appears in contrary to the laser spot welding with low constant feed speed. After the welding process, the two welding partners seem to not be joined together; instead, there is a small line between the two welding partners. We assume that this is caused by a native oxide on top of the welding partners before the welding process. On the other hand, the internal stress measurements show a very homogenous sample, and the stress values are low as compared to the other welding techniques. Unfortunately, the thickening of the silicon at the welding seam is a major problem. Therefore, this welding technique is not suitable to produce silicon foils for a roll to roll process.

Keyhole welding at room temperature is not performed due to the knowledge of the drastic changes within the silicon material and high inserted stress without preheating. However, the keyhole welding technique with preheated samples is successfully demonstrated. Furthermore, this welding process shows no newly formed grains after welding within the measurement accuracy. (Differences down to $1^{\circ}$ in crystal orientation can be detected with the EBSD measurement setup.) In addition, no thickening of silicon can be observed around the welding seam. Sample mappings occur to be homogenous. The locally occurring roughness on the back side of the silicon foil due to the laser irradiation is negligible for the solar cell device. Stress measurements determine moderate stress values for tensile as well as compressive stress, so that the mechanical stability is reassured. In summary, this welding technique offers the possibility of the manufacturing of extended monocrystalline silicon base foil in a roll to roll process. With these remarkable properties keyhole welding is the most favorable and promising process to produce silicon foils.

\section{Conclusions}

We have presented a comparison of three welding processes for ca. $50 \mu \mathrm{m}$ thin silicon foils: laser spot welding with low constant feed speed at room temperature, laser line welding at room temperature, and keyhole welding at preheated samples of $1015^{\circ} \mathrm{C}$. Welded thin silicon foils with the dimensions of up to $50 \times 25 \mathrm{~mm}^{2}$ are successfully demonstrated. The material properties of the thin silicon foils after the impact of the laser beam were analyzed by micro-Raman spectroscopy and electron backscatter diffraction.

The characterization revealed newly formed grains and grain boundaries at the welding seam for laser spot welding. Additionally, this technique suffers from the high inserted stress values after welding. Silicon thickening is observed for laser line welding at the junction of both welding partners. 
Thus, these two welding processes are not suitable for the production of thin silicon foils. Keyhole welding in comparison shows very homogenous material properties after laser irradiation. No evidence of newly formed grains or thickening at the welding seam could be found. Maximum tensile and compressive stress values are at a moderate level for keyhole welding higher than values for laser line welding, but lower for laser spot welding. Additionally, this technique can be performed in a configuration which leads to a flat silicon foil after welding. Therefore, keyhole welding is the most favorable process for welding several individual silicon thin wafers together to an extended monocrystalline silicon base foil. It should be interesting to investigate keyhole welding using double side polished wafer material. This could result in decreased internal stress values and higher mechanical stability of the silicon foils. The complex procedure of welding silicon needs further investigations as well as the support by a simulation model. Furthermore, solar cells on top of keyhole welded silicon foils are planned.

\section{Acknowledgments}

The authors thank the Deutsche Forschungsgemeinschaft (no.: KU 2601/1-2) for the financial support. Furthermore, the authors would like to acknowledge the technical assistance of Bernd Meidel and the sample preparation by Kerstin Schünemann and Georg Gries from Schott Solar AG in Alzenau (Germany).

\section{References}

[1] M. T. Hessmann, T. Kunz, I. Burkert et al., "Laser process for extended siliconthin film solar cells," Thin Solid Films, vol. 520, no. 1, pp. 595-599, 2011.

[2] T. Kunz, I. Burkert, R. Auer, and M. Zimmermann, "Towards extended free-standing crystalline silicon thin-films by laser joining," in Proceedings of the 22nd European Photovoltaic Solar Energy Conference, pp. 1946-1948, Milan, Italy, September 2007.

[3] R. Brendel, "A novel process for ultrathin monocrystalline silicon solar cells on glass," in Proceedings of the 14th European Photovoltaic Solar Energy Conference, pp. 1354-1357, Barcelona, Spain, June 1997.

[4] H. Tayanaka, K. Yamauchi, and T. Matsushita, "Thin-film crystalline silicon solar cells obtained by separation of a porous silicon sacrificial layer," in Proceedings of the 2nd World Conference and Exhibition on Photovoltaic Solar Energy Conversion, pp. 1272-1277, Vienna, Austria, 1998.

[5] T. Kunz, I. Burkert, M. Grosch, M. Scheffler, and R. Auer, "Spatial uniformity of large-area silicon layers $\left(43 \times 43 \mathrm{~cm}^{22}\right)$ grown by convection-assisted chemical vapor deposition," in Proceedings of the IEEE 4th World Conference on Photovoltaic Energy Conversion, pp. 1620-1623, Waikoloa, Hawaii, USA, May 2006.

[6] J. H. Petermann, D. Zielke, J. Schmidt, F. Haase, E. G. Rojas, and R. Brendel, "19\%-efficient and $43 \mu \mathrm{m}$-thick crystalline Si solar cell from layer transfer using porous silicon," Progress in Photovoltaics, vol. 20, no. 1, pp. 1-5, 2012.

[7] J. H. Werner, R. Dassow, T. J. Rinke, J. R. Köhler, and R. B. Bergmann, "From polycrystalline to single crystalline silicon on glass," Thin Solid Films, vol. 383, no. 1-2, pp. 95-100, 2001.
[8] S. Kaufmann, Grundlegende Untersuchungen zum Nd:YAG-Laserstrahlfügen von Silizium für Komponenten der Optoelektronik, Meisenbach, Bamberg, Germany, 2002.

[9] U. Gösele, Q. Y. Tong, A. Schumacher et al., "Wafer bonding for microsystems technologies," Sensors and Actuators A, vol. 74, no. 1-3, pp. 161-168, 1999.

[10] L. Schaefer, H. Koch, K. Tangermann-Gerk et al., "Laser based joining of monocrystalline silicon foils," Physics Procedia, vol. 5, pp. 503-510, 2010.

[11] L. Schaefer, S. Roth, and M. Heßmann, "Anforderungen an den Prozess und die Systemtechnik beim Laserstrahlschweißen von Silizium Zusammenfassung Einleitung Eigenschaften und Verarbeitbarkeit von Silizium," in Proceedings of the 13th Laser in der Elektronikproduktion und Feinwerktechnik, pp. 75-85, Fürth, Germany, 2010.

[12] R. Völkel and M. Zimmermann, "Homogenisierung von Laserstrahlen," Photonik, pp. 76-79, 2006.

[13] K. Cvecek, M. Zimmermann, U. Urmoneit, T. Frick, M. Heßmann, and T. Kunz, "Thermisches Prozessieren dünner Siliziumsubstrate für die solare Energieerzeugung," in Proceedings of the 15th Laser in der Elektronikproduktion und Feinwerktechnik, pp. 91-101, Fürth, Germany, 2012.

[14] T. Kunz, M. T. Hessmann, B. Meidel, and C. J. Brabec, "MicroRaman mapping on layers for crystalline silicon thin-film solar cells," Journal of Crystal Growth, vol. 314, no. 1, pp. 53-57, 2011.

[15] I. De Wolf, "Micro-Raman spectroscopy to study local mechanical stress in silicon integrated circuits," Semiconductor Science and Technology, vol. 11, no. 2, pp. 139-154, 1996.

[16] G. Sarau, M. Becker, G. Andrä, and S. Christiansen, "Residual stress measurements in multicrystalline silicon bulk and thin film solar cells using micro-Raman spectroscopy," in Proceedings of the 23rd European Photovoltaic Solar Energy Conference, pp. 2265-2270, Valencia, Spain, 2008.

[17] L. Eötvös, "Über den Zusammenhang der Oberflächenspannung der Flüssigkeiten mit ihrem Molekularvolumen," Annalen der Physik und Chemie, vol. 27, pp. 448-459, 1886.

[18] S. R. Palit, "Thermodynamic interpretation of the eötvös constant," Nature, vol. 177, no. 4521, p. 1180, 1956. 

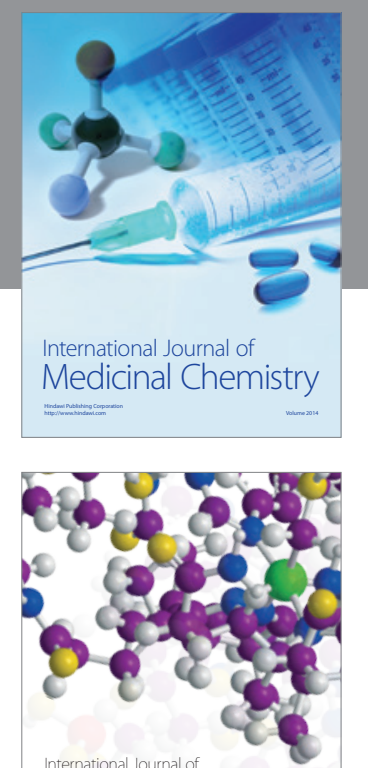

\section{Carbohydrate} Chemistry

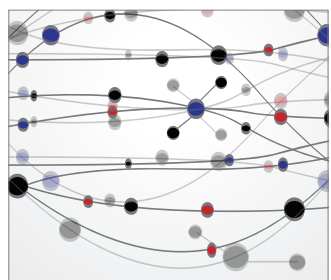

The Scientific World Journal
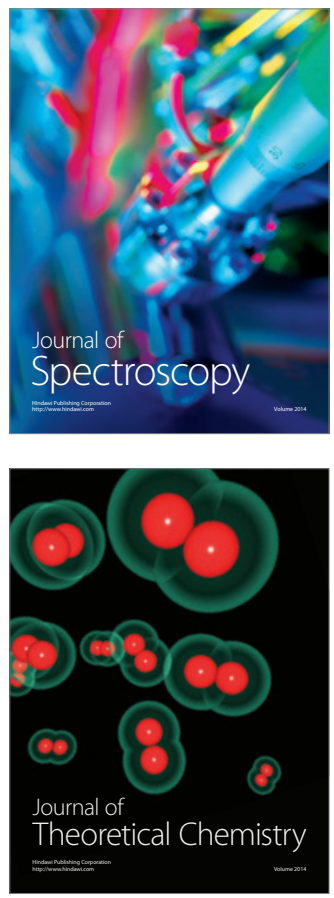
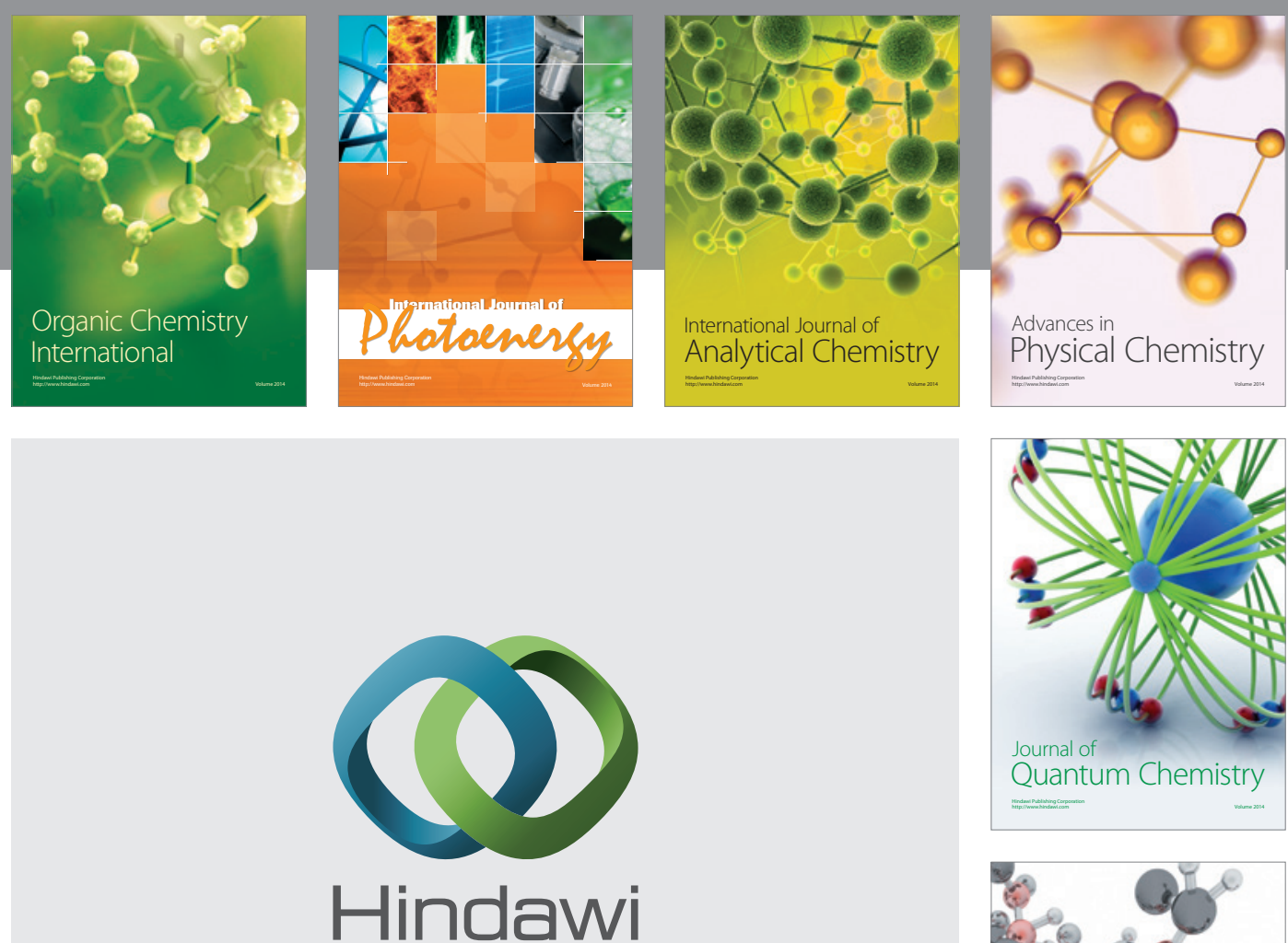

Submit your manuscripts at

http://www.hindawi.com

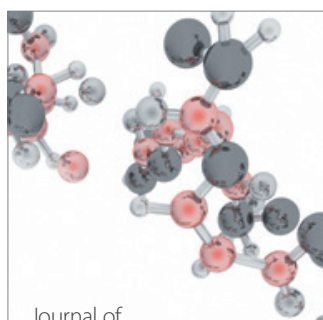

Analytical Methods

in Chemistry

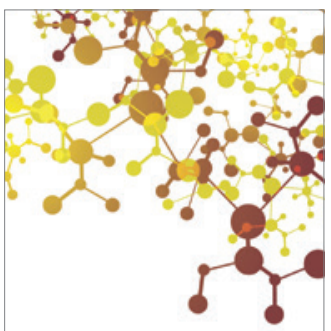

Journal of

Applied Chemistry

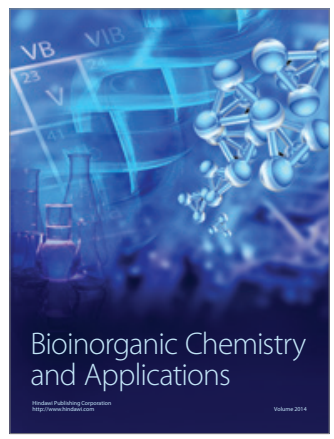

Inorganic Chemistry
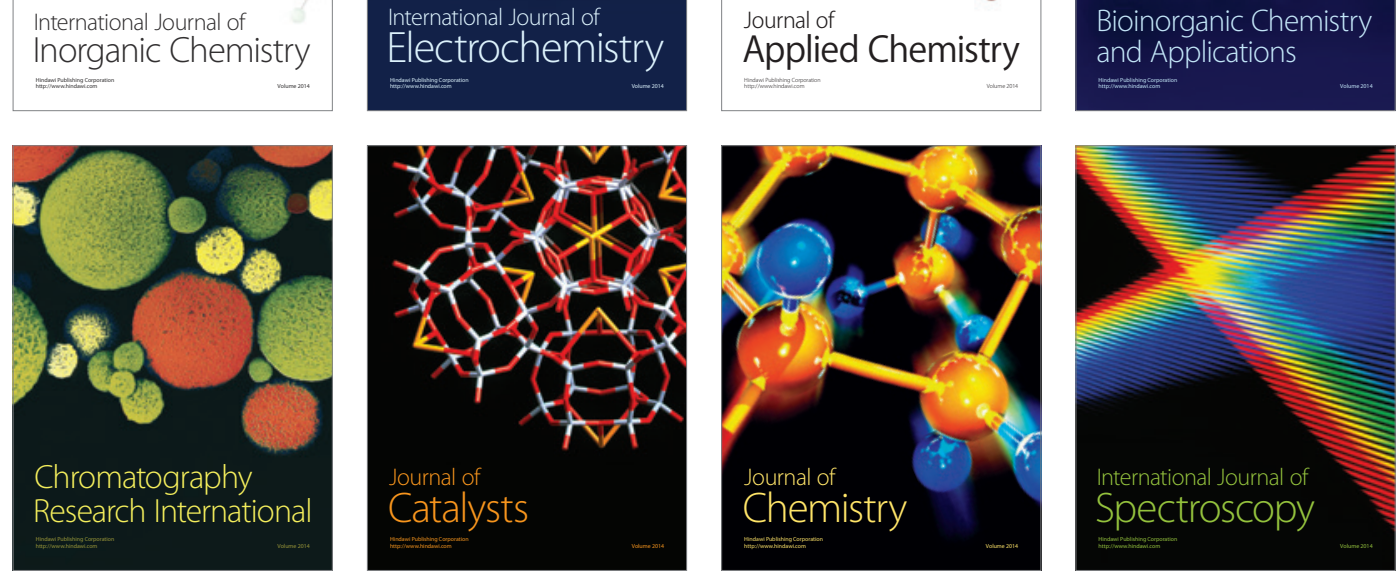